\title{
The Cerebral Extracellular Release of Glycerol, Glutamate, and FGF2 Is Increased in Older Patients following Severe Traumatic Brain Injury
}

Pekka Mellergard, Florence Sjögren and Jan Hillman

\section{Linköping University Post Print}

N.B.: When citing this work, cite the original article.

Original Publication:

Pekka Mellergard, Florence Sjögren and Jan Hillman, The Cerebral Extracellular Release of Glycerol, Glutamate, and FGF2 Is Increased in Older Patients following Severe Traumatic Brain Injury, 2012, Journal of Neurotrauma, (29), 1, 112-118.

http://dx.doi.org/10.1089/neu.2010.1732

Copyright: Mary Ann Liebert http://www.liebertpub.com/

Postprint available at: Linköping University Electronic Press http://urn.kb.se/resolve?urn=urn:nbn:se:liu:diva-75116 


\title{
The Cerebral Extracellular Release of Glycerol, Glutamate, and FGF2 Is Increased in Older Patients following Severe Traumatic Brain Injury
}

\author{
Pekka Mellergård, ${ }^{1}$ Florence Sjögren, ${ }^{2}$ and Jan Hillman ${ }^{1}$
}

\begin{abstract}
Old age is associated with a poor recovery from traumatic brain injury (TBI). In a retrospective study we investigated if the biochemical response following TBI is age dependent. Extracellular fluids were continuously sampled by microdialysis in 69 patients admitted to our NSICU following severe TBI. The concentrations of glycerol, glutamate, lactate, pyruvate, and eight different cytokines (IL-1 $\beta$, IL-6, IL-10, IL-8, MIP-1 $\beta$, RANTES, FGF2, and VEGF) were determined by fluorescence multiplex bead technology. Patients in the oldest age group ( $\geq 65$ years) had significantly higher microdialysate concentrations of glycerol and glutamate compared to younger patients: the mean microdialysate concentration of glycerol increased from $55.9 \mu \mathrm{mol} / \mathrm{L}$ ( $25-44$ year) to $252 \mu \mathrm{mol} / \mathrm{L}$ ( $\geq 65$ years; $p<0.0001)$; similarly glutamate increased from $15.8 \mathrm{mmol} / \mathrm{L}$ to $92.2 \mathrm{mmol} / \mathrm{L}$ $(p<0.0001)$. The lactate-pyruvate ratio was also significantly higher in the patients $\geq 65$ years of age (63.9) compared with all the other age groups. The patterns of cytokine responses varied. For some cytokines (IL-1b, IL-10, and IL-8) there were no differences between age groups, while for others (MIP-1b, RANTES, VEGF, and IL-6) some differences were observed, but with no clear correlation with increasing age. For FGF2 the mean microdialysate concentration was $43 \mathrm{pg} / \mathrm{mL}$ in patients $\geq 65$ years old, significantly higher compared to all other age groups $(p<0.0001)$. Increased concentrations of glycerol and glutamate would indicate more extensive damaging processes in the elderly. An increase in concentration of FGF2 could serve a protective function, but could also be related to a dysregulation of the timing in the cellular response in elderly patients.
\end{abstract}

Key words: cytokines; FGF2; glutamate; glycerol; microdialysis; monitoring; traumatic brain injury

\section{Introduction}

$T^{3}$ RAUMATIC BRAIN INJURY (TBI) is a significant problem in senior citizens, with old age being associated with a poor recovery from brain injury (Hukkelhoven et al., 2003; Livingston et al., 2005; Thompson et al., 2006). The poorer prognosis has prompted some investigators to advocate a more conservative approach in elderly patients with moderate and severe TBI (Gan et al., 2004). For several reasons, including the steady improvement of health in the elderly population, this attitude needs to be balanced with an ambition to improve the understanding of the age-specific responses, as well as the special needs, of the elderly brain. At the present, little is known about the efficacy of TBI treatment in older patients. Clearly, it is not age per se that is the cause of poor prognosis, but age-related factors that may be open to therapeutic interventions (Cekic and Stein, 2010; Fabbri et al., 2008). It is therefore important to achieve a greater under- standing of the pathophysiological processes following TBI in the elderly.

In this preliminary and retrospective study we used microdialysis to study the release of different metabolites and cytokines in the cerebral extracellular space following severe brain injury, and analyzed the data in order to detect possible age-related differences in the cerebral biochemical response to TBI. The study is part of an ongoing project, aimed at optimizing the care of NSICU patients (Mellergard et al., 2008, 2010, 2011).

\section{Methods \\ Patient sample}

The Ethical Committee of the University Hospital of Linköping granted ethical approval for the study. The study involved 69 patients (48 males and 21 females, mean age 45.9 years) admitted to the neurosurgical clinic of Linköping

${ }^{1}$ Department of Neurosurgery, ${ }^{2}$ Department of Dermatology, University Hospital, Linköping, Sweden. 
Table 1. Glasgow Outcome Scale Scores at 6-Month Follow-Up for Patients in Study

\begin{tabular}{lccccc}
\hline $\begin{array}{l}\text { GOS } \\
\text { (6 months) }\end{array}$ & $\begin{array}{c}<5 \\
\text { years }\end{array}$ & $\begin{array}{c}25-44 \\
\text { years }\end{array}$ & $\begin{array}{c}45-64 \\
\text { years }\end{array}$ & $\begin{array}{c}\geq 65 \\
\text { years }\end{array}$ & $\begin{array}{c}\text { All patients } \\
(\mathrm{n}=69)\end{array}$ \\
\hline GOS 1 & 1 & 2 & 10 & 8 & 21 \\
GOS 2 & 0 & 1 & 0 & 0 & 1 \\
GOS 3 & 0 & 3 & 8 & 0 & 11 \\
GOS 4 & 0 & 2 & 5 & 1 & 8 \\
GOS 5 & 7 & 4 & 4 & 1 & 16 \\
Unknown & 4 & 3 & 4 & 1 & 12 \\
Total & 12 & 15 & 31 & 11 & 69 \\
\hline
\end{tabular}

University Hospital for treatment of severe TBI. Due to the severity of their condition, all patients were treated in a specialized NSICU, with designated treatment protocols and multimodality monitoring allowing adjustment of therapy to meet individual needs. For trauma patients, our standard treatment protocol is based on the Lund concept (for more details, see Sturnegk et al., 2007).

Table 1 describes the age distribution and the outcome at 6 months as described by the Glasgow Outcome Scale (GOS). In the oldest age group ( $>65$ years) the GOS score was known for 10 of the 11 patients. As seen in Table 1, the outcomes of these patients were very poor, with a mortality rate of $80 \%$ at 6-month follow-up. However, while in the NSICU the large majority of these older patients were in stable condition. Only two patients in the oldest age group had prolonged periods of increased ICP (above $30 \mathrm{mmHg}$ ), in one patient this was combined with a longer period with CPP below $50 \mathrm{mmHg}$. Another four patients in this group had occasional readings of ICP above $25 \mathrm{mmHG}$, but never with the CPP going below $50 \mathrm{mmHg}$.

\section{Sampling of microdialysate}

Microdialysis has been an integrated part of the multimodality monitoring of seriously injured patients in the NSICU of Linköping University Hospital for many years. The insertion and handling of microdialysis catheters followed our normal routines as previously described in detail (Hillman et al., 2007; Mellergard et al., 2008). CMA71 catheters (with $100 \mathrm{kDa}$ cut-off) were perfused at a standardized flow of $0.3 \mathrm{~mL} / \mathrm{min}$ with Ringer-Dextran 60 (RD60, Braun Medical, Stockholm, Sweden) or poly- (0-2-hydroxyethyl) starch in $0.9 \%$ sodium chloride $\left(\right.$ Voluven $^{\circledR}{ }^{\circledR}$, Fresenius Kabi, Stockholm, Sweden), utilizing the CMA 106 perfusion pump (CMA Microdialysis, Stockholm, Sweden). For the first 63 patients the perfusate used was Ringer-Dextran 60; for the last seven patients the catheters were perfused with Voluven. The change of perfusate was due to withdrawal of Ringer-Dextran from the market, due to limited commercial demand. (When analyzing our total sample of close to 250 patients undergoing longer periods of microdialysis, in which $27 \%$ had been perfused with Voluven, we did not detect any differences in the pattern of recovery of biomolecules related to the type of perfusate.)

Two-hour samples were continuously collected and analyzed at bedside for glutamate, glycerol, lactate, and pyruvate using the CMA 600 analyzer (CMA Microdialysis). Consecutive $6 \mathrm{~h}$ samples were continuously collected and frozen $\left(-70^{\circ} \mathrm{C}\right)$ for later analyses in the laboratory.
We have previously shown significant and transient effects on extracellular interleukin concentrations associated with the insertion of a microdialysis catheter (Mellergard et al., 2008). In the present series of seriously injured NSICU patients with highly individual needs, the catheter insertion time could not be standardized. Data from the first $24 \mathrm{~h}$ following insertion of a catheter was therefore not used.

The microdialysate was analyzed for the content of interleukin-1 $\beta$ (IL-1 $\beta$ ), interleukin-6 (IL-6), interleukin-8 (IL-8), macrophage inflammatory protein $-1 \beta(\mathrm{MIP}-1 \beta)$, regulatedupon-activation normal T-cell expressed and secreted) (RANTES, also known as CCL-5), vascular endothelial growth factor (VEGF), and basic fibroblast growth factor (FGFb), with Fluorokine MAP Multiplex Assays for the Luminex platform (R\&D Systems, Oxford, United Kingdom), a method based on multiplex bead technology, as previously described (Mellergard et al., 2008). Briefly, different populations of polystyrene beads ( $5.6 \mu \mathrm{m}$ in diameter) are covalently coupled with an antibody directed against a specific cytokine. After reacting with the cytokines found in the sample, the bead-antibody-antigen complexes are allowed to react with detection antibody amplification, and analysis is performed on a Luminex 100 instrument (Biosource, Nivelles, Belgium) (Fulwyler and McHugh, 1990; Kemeny, 1992). IL-10 was measured with commercially available chemo-luminescence based enzyme-linked immunosorbent assays (ELISA Quantiglo, R\&D System). This method is capable of detecting sub-picogram concentrations. All assays were performed according to instructions from the manufacturer.

\section{Statistical analysis}

All analyses were made on pooled data (i.e., from all samples in all patients in respective age group during the whole observation period). Unpaired student $t$-test were used for most of the statistical evaluation, or, when appropriate, with ANOVA with post hoc Fischer's PLSD. In the accompanying visual images, data are presented in boxplots, with the box representing observations between the 25 th and 75 th percentile, the lower bar being the 10th percentile and the upper bar the 90th percentile. The horizontal line within each box represents the 50th percentile (median). The level of significance was set at $p<0.05$. Mean values are presented together with standard error of the mean (SEM).

\section{Results}

\section{Concentration of metabolites in patients in different age groups}

The patients were divided into four different age groups: $<25$ years, $25-44$ years, $45-64$ years, $\geq 65$ years. When analyzed with ANOVA, gradual and highly significant increases in the mean concentrations of glycerol and glutamate were observed in the three oldest age groups (Fig. 1 and Table 2). Thus, the mean microdialysate concentration of glycerol increased from $55.9 \mu \mathrm{mol} / \mathrm{L}$ (25-44 years) to $88.4 \mathrm{pg} / \mathrm{mL}$ (45-65 years) to $252 \mathrm{pg} / \mathrm{mL}$ ( $\geq 65$ years; $p<0.0001$ ). Similarly, the mean microdialysate concentration of glutamate increased from $15.8 \mathrm{mmol} / \mathrm{L}$ (25-44 years) to $41.0 \mathrm{mmol} / \mathrm{L}$ (45-65 years) to $92.2 \mathrm{mmol} / \mathrm{L}$ ( $\geq 65$ years; $p<0.0001$ ). Although similar patterns were observed for lactate, pyruvate, and the lactatepyruvate ratio (Fig. 1C), the concentration patterns were more 

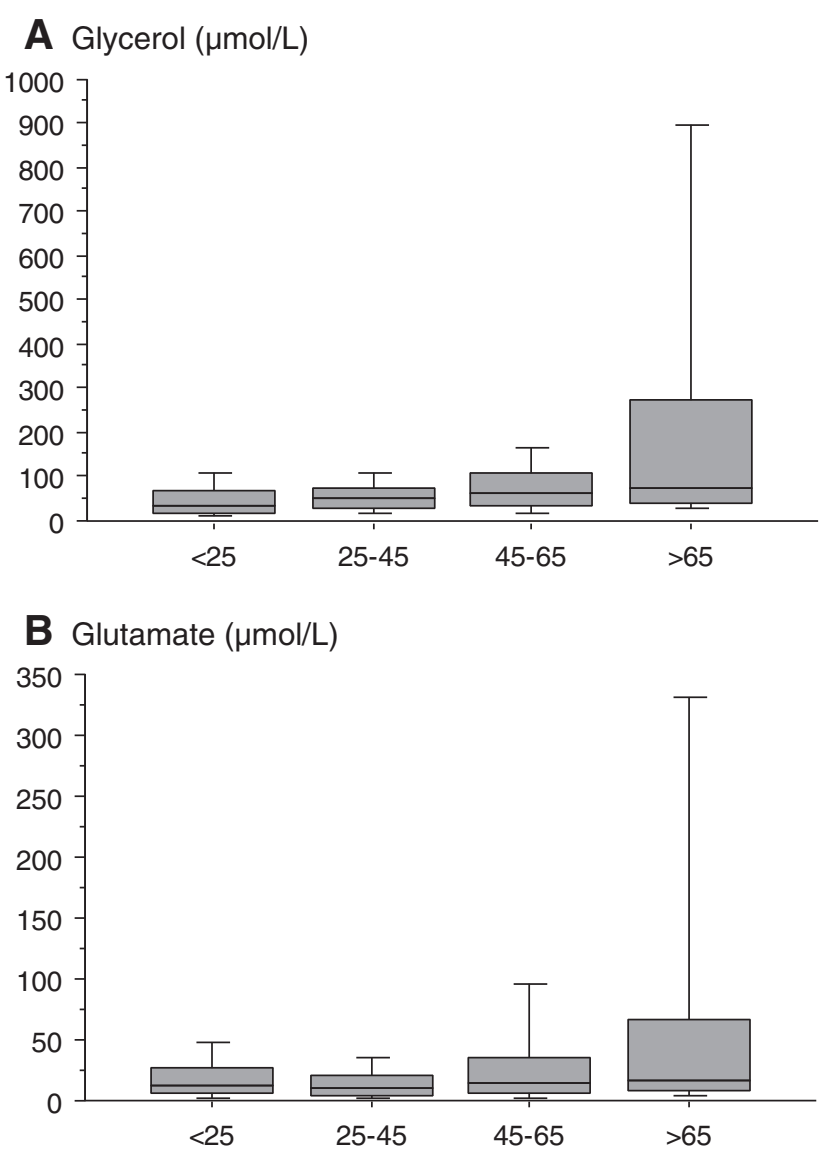

C Lactate/pyruvate-ratio

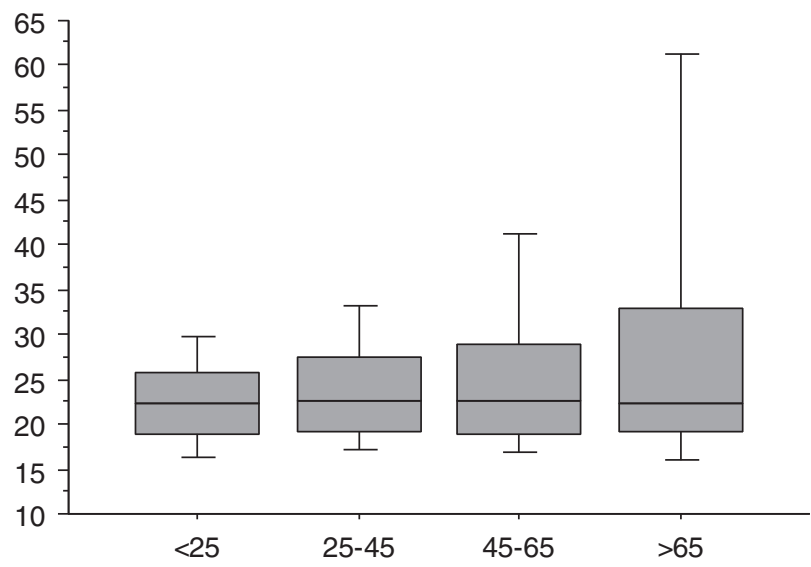

FIG. 1. Plots showing differences in concentrations (in pg/ $\mathrm{mL}$ ) of glycerol (A), glutamate (B), and the lactate-pyruvate (C) in microdialysate sampled from patients in four different age groups ( $<25$ years, $25-44$ years, $45-64$ years, $\geq 65$ years, for details, see text).

complex (Table 2). However, the lactate-pyruvate ratio was significantly higher in patients $\geq 65$ years of age (63.9) compared with those in the other age groups (23.5-26.9).

There were six patients older than 70 years. When these patients were compared with the rest, the difference in glycerol and glutamate concentrations appeared more pronounced. Thus, the mean microdialysate concentration of glycerol was $469.6 \mathrm{pg} / \mathrm{mL}$ in patients $>70$ years of age (i.e.,
5.8 times higher compared patients $<70$ years; $p<0.0001)$. Similarly, the mean microdialysate concentration of glutamate was $123 \mathrm{mmol} / \mathrm{L}$ in patients 70 years or above, 3.8 times higher than in patients below 70 years of age $(p<0.0001)$.

\section{Concentration of cytokines in patients in different age groups}

The results of the analysis of eight different cytokines are presented in Table 3 and Figure 2. For three of the cytokines (IL-1b, IL-10, and IL-8), there were no differences in the mean microdialysate concentration between any of the four age groups. For two other cytokines (MIP-1b and RANTES), the difference observed between two groups ( $<25$ years vs. $45-65$ years) barely reached significance $(p=0.03-0.04)$.

VEGF was lowest in the youngest age group $(11.6 \mathrm{pg} / \mathrm{mL})$, significantly so when compared with the two intermediate age groups. The mean microdialysate concentration of IL- 6 was $1822 \mathrm{pg} / \mathrm{mL}$ in patients aged $45-65$ years, significantly higher compared to the other three groups.

The most obvious observation involved FGF2, where the mean microdialysate concentration was $43 \mathrm{pg} / \mathrm{mL}$ in patients $\geq 65$ years old, significantly higher compared to all other age groups $(p<0.0001)$. When comparing patients older or younger than 70 years, there were no differences in mean concentrations for any cytokines, with the exception of FGF2.Thus, the mean concentration of FGF2 in the patients $>70$ years of age was $51.8 \pm 12.6 \mathrm{pg} / \mathrm{mL}$ (3.6 times higher than the mean value for patients $<70$ years, $p<0.0001)$.

\section{Comparison of patients with fatal outcome}

As seen in Table 1, patients that were 65 years or older had a much worse outcome compared to those in the other age groups, with $80 \%$ of patients $\geq 65$ (with a known GOS score) not surviving to the 6-month follow-up. We therefore analyzed all patients with a known GOS of 1 (i.e., dead), comparing patients $\geq 65$ years with those $<65$ years of age. As seen in Table 4, when patients with fatal outcomes were compared, the differences described above remained. Thus, the mean values for glycerol, glutamate, the lactate-pyruvate ratio, and FGF2 observed in the NSICU were significantly higher in the patients $\geq 65$ years of age compared with the patients $<65$ years, even if they were dead at 6 -month follow-up.

\section{Discussion}

Traumatic brain injury (TBI) in older adults is a significant public health issue, with, for example, adults in the US aged 75 and older having the highest rates of TBI-related hospitalization and death (Thompson et al., 2006). Unfortunately, increasing age is strongly associated with a poor prognosis both in experimental trauma models and following TBI in humans (Livingston et al., 2005; Onyszchuk et al., 2008; Rothweiler et al., 1998; Sendroy-Terrill et al., 2010; Susman et al., 2002). Confirmed factors of poor prognosis for patients with GCS 3 or 4 and older than 65 years are closed basal cisterns and midline shift $>15 \mathrm{~mm}$ on the first CT (Brazinova et al., 2010). The worse outcomes in elderly human subjects occur despite what appears to be less severe TBI, as measured by a higher GCS upon admission (Livingston et al., 2005; Susman et al., 2002). 
Table 2. (A) Concentration of Metabolites in Four Age Groups. (B) Significance Levels in Groups Compared and ANAlyzed with ANOVA

\begin{tabular}{lrrrr}
\hline A & \multicolumn{1}{c}{$<25$} & \multicolumn{1}{c}{$25-45$} & \multicolumn{1}{c}{$45-65$} & $>65$ \\
\hline Glycerol $(\mu \mathrm{mol} / \mathrm{L})$ & $63.8 \pm 4.40(981)$ & $55.9 \pm 1.16(1289)$ & $88.4 \pm 2.81(1478)$ & $252 \pm 15.7(568)$ \\
Glutamate $(\mathrm{mmol} / \mathrm{L})$ & $21.2 \pm 0.94(1046)$ & $15.8 \pm 0.42(1260)$ & $41.0 \pm 2.05(1610)$ & $92.2 \pm 6.82(645)$ \\
Lactate $(\mathrm{mmol} / \mathrm{L})$ & $5.0 \pm 0.06(1079)$ & $5.0 \pm 0.06(1289)$ & $6.5 \pm 0.08(1655)$ & $6.3 \pm 0.13(662)$ \\
Pyruvate $(\mathrm{mmol} / \mathrm{L})$ & $221 \pm 2.55(1074)$ & $216 \pm 2.43(1286)$ & $256 \pm 2.73(1661)$ & $227 \pm 4.20(648)$ \\
L/P ratio & $23.5 \pm 0.29(1074)$ & $26.4 \pm 0.96(1285)$ & $26.9 \pm 0.34(1654)$ & $63.9 \pm 7.62(648)$ \\
\hline
\end{tabular}

Number of measurements is given in parentheses.

\begin{tabular}{|c|c|c|c|c|c|}
\hline B & Glycerol & Glutamate & Lactate & Pyruvate & $L / P$ ratio \\
\hline$<25$ vs $25-45$ & ns & ns & ns & ns & ns \\
\hline$<25$ vs $45-65$ & 0.0003 & $<0.0001$ & $<0.0001$ & $<0.0001$ & ns \\
\hline$<25$ vs $>65$ & $<0.0001$ & $<0.0001$ & $<0.0001$ & ns & $<0.0001$ \\
\hline $25-45$ vs $45-65$ & $<0.0001$ & $<0.0001$ & $<0.0001$ & $<0.0001$ & ns \\
\hline $25-45$ vs > 65 & $<0.0001$ & $<0.0001$ & $<0.0001$ & 0.0164 & $<0.0001$ \\
\hline $45-65$ vs $>65$ & $<0.0001$ & $<0.0001$ & ns & $<0.0001$ & $<0.0001$ \\
\hline
\end{tabular}

ANOVA, post-hoc PLSD; ns, not significant.

Several clinical reports from the last decade have shown that the age-related worsening of prognosis following TBI is not a phenomenon related only to very advanced age. In a large sample of 5600 TBI patients, Hukkelhoven and colleagues (2003) reported that the association between age and unfavorable/fatal outcome was continuous and could be adequately described in linear terms. These investigators found that the odds for a poor outcome increased by $40-50 \%$ per 10 years of age. Harris and colleagues (2003) reported that the risk of dying for patients suffering from head injuries increases as early as 30 years of age, while Livingstone and colleagues (2005) described that differences in functional outcome at one year after TBI begin to appear in patients between 45 and 59 years.
Despite the evidence that outcomes from TBI are related to age, there has been little research to explore potential mechanisms that can explain this phenomenon. From experimental studies it appears that the aged brain is more vulnerable to secondary processes, like prolonged acute edema, increased opening of the blood-brain barrier, and increased oxidative stress due to a relative shortage of freeradical scavengers, all of which would lead to increased neurodegeneration and a greater loss of function in the aged brain (Onyszchuk et al., 2008; Slemmer et al., 2008). It has been proposed that elevated basal levels of corticosterone present in aged animals may mediate the enhanced vulnerability of aged animals to TBI (White-Gbadebo and Hamm, 1993).

Table 3. (A) Concentration of Cytokines (pg/mL) in Four Age Groups. (B) Significance LEVEls in Groups ANALYZED with ANOVA

\begin{tabular}{lccrc}
\hline A & $\begin{array}{c}<5 \text { years } \\
(\mathrm{n}=12)\end{array}$ & $\begin{array}{c}25-44 \text { years } \\
(\mathrm{n}=15)\end{array}$ & $\begin{array}{c}45-64 \text { years } \\
(\mathrm{n}=31)\end{array}$ & $\begin{array}{c}\geq 65 \text { years } \\
(\mathrm{n}=11)\end{array}$ \\
\hline IL-1b & $11.3 \pm 1.69(188)$ & $15.2 \pm 2.07(228)$ & $23.0 \pm 8.70(277)$ & $11.3 \pm 2.22(124)$ \\
IL-6 & $533 \pm 63.3(203)$ & $831 \pm 125(250)$ & $1822 \pm 301(302)$ & $932 \pm 134(149)$ \\
IL-10 & $11.1 \pm 1.66(35)$ & $17.4 \pm 4.26(57)$ & $11.8 \pm 2.46(79)$ & $12.3 \pm 3.63(22)$ \\
IL-8 & $1122 \pm 107(200)$ & $1346 \pm 147(245)$ & $1196 \pm 89.2(292)$ & $993 \pm 68.0(128)$ \\
MIP-1b & $323 \pm 28.4(199)$ & $267 \pm 24.6(258)$ & $251 \pm 19.6(290)$ & $294 \pm 26.8(119)$ \\
RANTES & $29.9 \pm 3.95(154)$ & $93.6 \pm 33.0(192)$ & $103.4 \pm 26.3(217)$ & $42.4 \pm 7.62(115)$ \\
FGF2 & $14.6 \pm 3.61(85)$ & $10.0 \pm 0.63(142)$ & $12.8 \pm 1.42(158)$ & $43.0 \pm 7.58(79)$ \\
VEGF & $11.6 \pm 1.96(122)$ & $60.1 \pm 16.2(155)$ & $67.7 \pm 17.4(198)$ & $21.3 \pm 6.18(70)$ \\
\hline
\end{tabular}

$n=$ number of patients; number of measurements is given in parentheses.

\begin{tabular}{|c|c|c|c|c|c|c|c|c|}
\hline B & $I L-1$ & $I L-6$ & IL-10 & $I L-8$ & $M I P-1 b$ & RANTES & $F G F-2$ & VEGF \\
\hline$<25$ vs $25-45$ & Ns & ns & ns & ns & ns & ns & ns & 0.0304 \\
\hline$<25$ vs $45-65$ & Ns & $<0.0001$ & ns & ns & 0.0327 & 0.0352 & ns & 0.0085 \\
\hline$<25$ vs $>65$ & ns & ns & ns & ns & ns & ns & $<0.0001$ & ns \\
\hline $25-45$ vs $45-65$ & ns & 0.0005 & ns & ns & ns & ns & ns & ns \\
\hline $25-45$ vs > 65 & ns & ns & ns & ns & ns & ns & $<0.0001$ & ns \\
\hline $45-65$ vs $>65$ & ns & 0.0071 & ns & ns & ns & ns & $<0.0001$ & ns \\
\hline
\end{tabular}

ANOVA, post hoc PLSD; ns, not significant. 

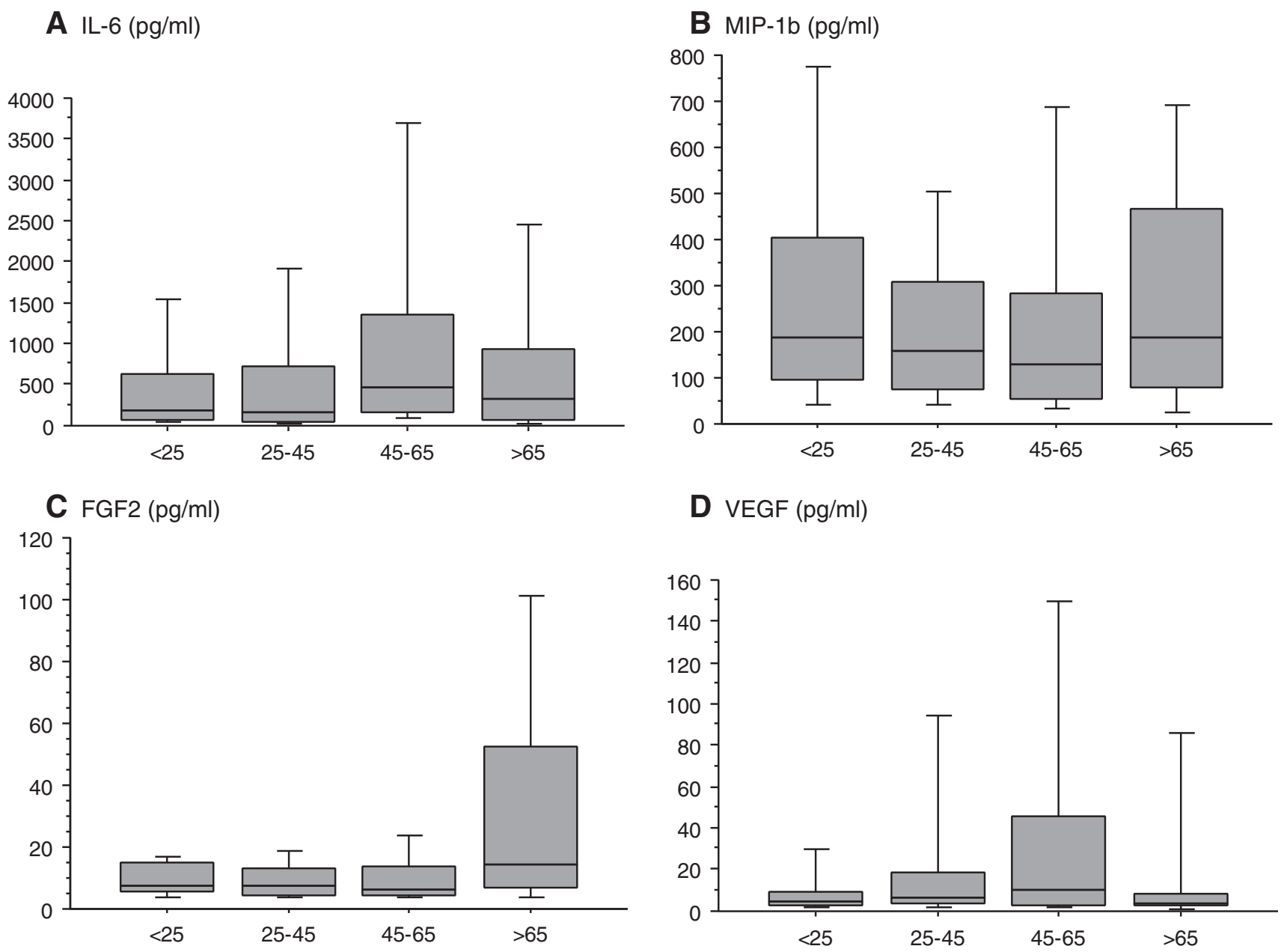

FIG. 2. Box plots showing the differences in concentrations (pg/mL) of IL-6 (A), MIP-1 $\beta$ (B), FGF2 (C), and VEGF (D) in microdialysate sampled from patients in four different age groups ( $<25$ years, $25-44$ years, $45-64$ years, $\geq 65$ years).

To our knowledge, conclusive age-related biochemical data from the human brain following TBI is entirely lacking. Although from a limited sample, the present results are therefore of interest, indicating that also in the human brain age is a determinant for the pathophysiological processes following severe traumatic brain injury.

It is generally accepted that excitatory amino acids play an important role in the development of cell damage following cerebral ischemia and trauma (Hazell, 2007; Matute et al., 2006) and the concentration of interstitial glycerol is generally assumed to reflect the degree of cell membrane degradation (i.e., destruction of cerebral tissue) (Frykholm et al., 2001; Ståhl and Nordström, 2001; Ungerstedt et al., 1997). The gradual age-related increase in the mean microdialysate concentrations of glutamate and glycerol observed in our study are thus consistent with an expected poor prognosis associated with increasing age. The age-related increase in the lactat-/pyruvate ratio that was also observed may partly explain the increased damage, as it points to a role of insufficient utilization of oxygen in elderly patients.

The patterns of cytokine responses observed in our study were complex. For some cytokines (IL-1b, IL-10, and IL-8),

Table 4. Lactate-Purvate Ratio and Mean Concentration ( \pm SEM) of Glycerol, Glutamate, and FGF2 in Patients with GOS Of 1 at 6-Month Follow-Up

\begin{tabular}{lcrr}
\hline & \multicolumn{1}{c}{$<65(\mathrm{n})$} & $>65(\mathrm{n})$ & $\mathrm{p}$ value \\
\hline Glycerol $(\mu \mathrm{mol} / \mathrm{L})$ & $92.1 \pm 6.32(599)$ & $283.6 \pm 20.12(435)$ & $<0.0001$ \\
Glutamate $(\mathrm{mmol} / \mathrm{L})$ & $61.1 \pm 4.65(655)$ & $113.2 \pm 8.35(512)$ & $<0.0001$ \\
Lactate-pyruvate $(\mathrm{mmol} / \mathrm{L})$ & $27.1 \pm 0.69(660)$ & $74.6 \pm 9.54(515)$ & $<0.0001$ \\
FGF2 $(\mathrm{pg} / \mathrm{mL})$ & $19.9 \pm 5.84(56)$ & $58.7 \pm 10.20(55)$ & 0.0012 \\
\hline
\end{tabular}

Number of measurements is given in parentheses. 
there was no indication of age being a determining factor for the release into the cerebral extracellular space. For other cytokines (MIP-1b, RANTES, VEGF, and IL-6), some differences were observed between age groups, but with no clear correlation with increasing age.

The most interesting observation was the significant difference in the mean dialysate concentration of FGF2 in the oldest patients compared with that of other age groups. This was an unexpected finding since FGF2 is generally thought as having an important role in recovery from brain damage (Monfils et al., 2005; Mudò et al., (2009; Yoshimura et al., 2001). However, based on data from experimental stroke models, it has been proposed that the timing of the cellular and genetic response to cerebral insult is dysregulated in aged animals. Thus, following stroke the critical, age-related differences apparent in the cytological response is accompanied by acceleration of the establishment of the glial scar (Petcu et al., 2008; Popa-Wagner et al., 2007). It is plausible that a similar mechanism could be at work following TBI. If so, an increase in the FGF2 response could be a factor of importance.

Clearly, the interpretation of the present data has to be made with caution. Patients with severe TBI always represent a heterogenous group, with an array of different factors influencing the clinical course. The sample is too small to be analyzed in a continuous, non-discrete manner as recommended by Hukkelhoven and colleagues (2003) and our choices of age limits are arbitrary. There were only 11 patients in the older age group ( $>65$ years of age), and we have not corrected for the exact length of monitoring in patients belonging to different age groups. Nevertheless, due to the previous lack of information on this subject, and with respect for some potentially important observations made, we believe the results are of interest to a wider audience.

\section{Conclusion}

With its limitations, the present study supports the hypothesis that age is one determining factor in the response of the human brain following severe traumatic brain injury. The age-related increase in the concentrations of glycerol and glutamate points to more extensive damaging processes in the elderly. The increase in lactate-pyruvate ratio indicates that one reason for this more extensive damage could be insufficient oxygen supply or utilization. The most interesting observation of the study is the age-dependent increase in the concentration of FGF2. This would actually be expected to serve a protective function. However, it may also support a hypothesis claiming that poorer prognosis in elderly patients following TBI and other types of brain injury is related to a dysregulation of the timing in the cellular response.

\section{Author Disclosure Statement}

No competing financial interests exist.

\section{References}

Brazinova, A., Mauritz, W., Leitgeb, J., Wilbacher, I., Majdan, M., Janciak, I., and Rusnak, M. (2010). Outcomes of patients with severe traumatic brain injury who have Glasgow Coma Scale scores of 3 or 4 and are over 65 years old. J. Neurotrauma 27, 1549-1555.

Cekic, M., and Stein, D.G. (2010). Traumatic brain injury and aging: is a combination of progesterone and vitamin D hor- mone a simple solution to a complex problem? Neurotherapeutics 7, 81-90.

Fabbri, A., Servadei, F., Marchesini, G., Stein, S.C., and Vandelli, A. (2008). Early predictors of unfavourable outcome in subjects with moderate head injury in the emergency department. J. Neurol. Neurosurg. Psychiatry 79, 567-573.

Frykholm, P., Hillered L, Långström, B., Persson, L., Valtysson, J., Watanabe, Y., and Enblad, P. (2001). Increase of interstitial glycerol reflects the degree of ischaemic brain damage: a PET and microdialysis study in a middle cerebral artery occlusionreperfusion primate model. J. Neurol. Neurosurg. Psychiatry $71,455-461$.

Fulwyler, M., and McHugh, T. (1990). Flow microshere immunoassay for the quantitative and simultaneous detection of multiple soluble analytes. Methods Cell Biol. 33, 613-629.

Gan, B.K., Lim, J.H., and Ng, I.H. (2004). Outcome of moderate and severe traumatic brain injury amongst the elderly in Singapore. Ann. Acad. Med. Singapore 33, 63-67.

Harris, C., DiRusso, S., Sullivan, T., and Benzil, D.L. (2003). Mortality risk after head injury increases at 30 years. J. Am. Coll. Surg. 197, 711-716.

Hazell, A.S. (2007). Excitotoxic mechanisms in stroke: an update of concepts and treatment strategies. Neurochem. Int. 50, 941953.

Hillman, J., Åneman, O., Persson, M., Andersson, C., Dabrosin, C., and Mellergård, P. (2007). Variations in the response of interleukins in neurosurgical intensive care patients monitored using intracerebral microdialysis. J. Neurosurg. 106, $820-825$.

Hukkelhoven, C.W., Steyerberg, E.W., Rampen, A.J., Farace, E., Habbema, J.D., Marshall, L.F., Murray, G.D., and Maas, A.I. (2003). Patient age and outcome following severe traumatic brain injury: an analysis of 5600 patients. J. Neurosurg. 99, 666-673.

Kemeny, D. (1992). Titration of antibodies. J. Immunol. Methods $150,57-76$.

Livingston, D.H., Lavery, R.F., Mosenthal, A.C., Knudson, M.M., Lee, S., Morabito, D., Manley, G.T., Nathens, A., Jurkovich, G., Hoyt, D.B., and Coimbra, R. (2005). Recovery at one year following isolated traumatic brain injury: a Western Trauma Association prospective multicenter trial. J. Trauma 59, 12981304.

Matute, C., Domercq, M., and Sanchez-Gomez, M.V. (2006). Glutamate-mediated glial injury: mechanisms and clinical importance. Glia 53, 212-224.

Mellergard, P., Aneman, O., Sjögren, F., Pettersson, P., and Hillman, J. (2008). Changes in extracellular concentrations of some cytokines, chemokines, and neurotrophic factors after insertion of intracerebral microdialysis catheters in neurosurgical patients. Neurosurgery 62, 151-157.

Mellergard, P., Åneman, O., Sjögren, F., and Hillman, J. (2010). Release of VEGF \& FGF in the extracellular space following subarachnoidal haemorrhage or traumatic head injury in humans. Brit. J. Neurosurg. 24, 261-267.

Mellergard, P., Åneman, O., Sjögren, F., Säberg, C., and Hillman, J. (2011). Differences in cerebral extracellular response of interleukin $1 \beta$, interleukin-6, and interleukin-10 following subarachnoidal haemorrhage or trauma in humans. Neurosurgery, 68(1), 12-19.

Monfils, M.H., Driscoll, I., Vandenberg, P.M., Thomas, N.J., Danka, D., Kleim, J.A., and Kolb, B. (2005). Basic fibroblast growth factor stimulates functional recovery after neonatal lesions of motor cortex in rats. Neuroscience 134, 1-8. 
Mudò, G., Bonomo, A., Di Liberto, V., Frinchi, M., Fuxe, K., and Belluardo, N. (2009). The FGF-2/FGFRs neurotrophic system promotes neurogenesis in the adult brain. J. Neural Transm. 116, 995-1005.

Onyszchuk, G., He, Y.Y., Berman, N.E., and Brooks, W.M. (2008). Detrimental effects of aging on outcome from traumatic brain injury: a behavioral, magnetic resonance imaging, and histological study in mice. J. Neurotrauma 25, 153-171.

Petcu, E.B., Sfredel, V., Platt, D., Herndon, J.G., Kessler, C., and Popa-Wagner, A. (2008). Cellular and molecular events underlying the dysregulated response of the aged brain to stroke: a mini-review. Gerontology 54, 6-17.

Popa-Wagner, A., Carmichael, S.T., Kokaia, Z., Kessler, C., and Walker, L.C. (2007). The response of the aged brain to stroke: too much, too soon? Curr. Neurovasc. Res. 4, 216-227.

Rothweiler, B., Temkin, N.R., and Dikmen, S.S. (1998). Aging effect on psychosocial outcome in traumatic brain injury. Arch. Phys. Med. Rehabil. 79, 881-887.

Sendroy-Terrill, M., Whiteneck, G.G., and Brooks, C.A. (2010). Aging with traumatic brain injury: cross-sectional follow-up of people receiving inpatient rehabilitation over more than 3 decades. Arch. Phys. Med. Rehabil. 91, 489-497.

Slemmer, J.E., Shacka, J.J., Sweeney, M.I., and Weber, J.T. (2008). Antioxidants and free radical scavengers for the treatment of stroke, traumatic brain injury and aging. Curr. Med. Chem. 15, 404-414.

Sturnegk, P., Mellergård, P., Yonas, H., Theodorsson, A., and Hillman, J. (2007). Potential use of quantitative bedside CBF monitoring $(\mathrm{Xe}-\mathrm{CT})$ for decision making in neurosurgical intensive care. Brit. J. Neurosurg. 21, 332-339.

Ståhl, N., Ungerstedt, U., and Nordström, C.H. (2001). Brain energy metabolism during controlled reduction of cerebral perfusion pressure in severe head injuries. Intensive Care Med. 27, 1215-1223.
Susman, M., DiRusso, S.M., Sullivan, T., Risucci, D., Nealon, P., Cuff, S., Haider, A., and Benzil, D. (2002). Traumatic brain injury in the elderly: increased mortality and worse functional outcome at discharge despite lower injury severity. J. Trauma 53, 219-223; discussion 223-214.

Thompson, H.J., McCormick, W.C., and Kagan, S.H. (2006). Traumatic brain injury in older adults: epidemiology, outcomes, and future implications. J. Am. Geriatr. Soc. 54, 15901595.

Ungerstedt, U., Rostami, E., Bäckström., T., Hallström, Å., Grände, P.O., Mellergård, P., and Nordström, C.H. (1997). Microdialys in normal and injured human brain, in: Physiology, Stress, Malnutrition: Functional Correlates, Nutrional Intervention. J.M. Kinney and H.N. Tucker (eds). Lippincott-Raven: Philadelphia, 1997, pps. 361-374.

White-Gbadebo, D., and Hamm, R.J. (1993). Chronic corticosterone treatment potentiates deficits following traumatic brain injury in rats: implications for aging. J. Neurotrauma 10, 297306.

Yoshimura, S., Takagi, Y., Harada, J., Teramoto, T., Thomas, S.S., Waeber, C., Bakowska, J.C., Breakefield, X.O., and Moskowitz, M.A. (2001). FGF-2 regulation of neurogenesis in adult hippocampus after brain injury. Proc. Natl. Acad. Sci. USA 98, 5874-5879.
Address correspondence to: Pekka Mellergård, M.D., Ph.D. Neurosurgical Department Linköping University Hospital S-581 85 Linköping Sweden

E-mail: pekka.mellergard@efk.se 